(2) Open Access Full Text Article

REVIEW

\title{
Impact of space flight on bacterial virulence and antibiotic susceptibility
}

This article was published in the following Dove Press journal:

Infection and Drug Resistance

30 July 2015

Number of times this article has been viewed

\section{Peter William Taylor \\ School of Pharmacy, University College London, London, UK}

Correspondence: Peter William Taylor School of Pharmacy, University College London, 29-39 Brunswick Square, London WCIN IAX, UK

Tel +442077535867

Fax +44 2077535942

Email peter.taylor@ucl.ac.uk
Abstract: Manned space flight induces a reduction in immune competence among crew and is likely to cause deleterious changes to the composition of the gastrointestinal, nasal, and respiratory bacterial flora, leading to an increased risk of infection. The space flight environment may also affect the susceptibility of microorganisms within the spacecraft to antibiotics, key components of flown medical kits, and may modify the virulence characteristics of bacteria and other microorganisms that contaminate the fabric of the International Space Station and other flight platforms. This review will consider the impact of true and simulated microgravity and other characteristics of the space flight environment on bacterial cell behavior in relation to the potential for serious infections that may appear during missions to astronomical objects beyond low Earth orbit.

Keywords: Staphylococcus aureus, International Space Station, microgravity, bacterial phenotypes, low-shear modeled microgravity, spacecraft contamination

\section{Introduction}

A new chapter in human space flight is opening: at one end of the spectrum, a fledging space tourism industry has emerged, and for the first time in many years, the possibility of exploration beyond low Earth orbit (LEO) is firmly on the agenda. As more nation states become involved, the momentum of manned space flight will inevitably increase and will eventually extend humanity's reach far into the solar system. The current focus of human activity in space is the International Space Station (ISS), the largest, most complex international scientific and engineering project conceived to date. The ISS has been continuously occupied since November 2000 and is likely to function as a research base for another 5-10 years. The ISS provides a platform for on-orbit long-duration (up to 215 days) studies to examine the impact of the space flight environment on human health and physiology and an opportunity to develop countermeasures that will sustain crew health during voyages into deep space. Although the enormous cost of building and maintaining the ISS has imposed severe financial and political constraints on planning missions beyond LEO, intent has been signaled for a return to the Moon and manned expeditions to Mars, near-Earth asteroids such as Ida and protoplanets in the asteroid belt such as Ceres, which are likely within the next $30-50$ years. ${ }^{1}$ For example, in spite of formidable technical, physical, and psychological barriers, NASA is developing capabilities to send human beings to an asteroid by 2025 and to Mars in the 2030s. In addition to exploratory missions, commercial-industrial activities may open up the potential for mining of minerals and fuel on the Moon or near-Earth asteroids.,3 Expeditions beyond Earth orbit present 
huge challenges in order to maintain the health of those on board. ${ }^{4-8}$ Lunar missions will last weeks or months and Martian expeditions will be of 2-3 years duration with little or no opportunity for evacuation of sick crew members should a medical emergency arise. In contrast, ISS crew typically spend 6 months on the platform and comprehensive plans are in place for immediate emergency evacuation. ${ }^{9}$ Crew on short-duration missions frequently experience minor trauma, burns, dermatological and musculoskeletal conditions, respiratory problems, headache, insomnia, and, most common of all, space motion sickness. ${ }^{5,10}$ In consequence, the crew members are trained to adopt first-aid treatments, resuscitation procedures, and other interventions including wound stitching and injection, ${ }^{11}$ which are supported by remote monitoring and distance support by Earth-based clinical specialists ${ }^{12}$ and an onboard medical kit containing a wide range of medications, including a substantial number of antibiotics formulated for topical and systemic use. ${ }^{13,14}$ There is no documented evidence that microbial infection has led to the abortion of a space flight but localized infections have caused significant problems during orbital missions; these include conjunctivitis and acute respiratory and dental infections. ${ }^{4}$ Among the most prominent was a severe dental infection suffered by cosmonaut Yury Romanenko during an extended flight aboard Salyut 6. He suffered debilitating toothache for $>2$ weeks, which was only remedied on his return to the Earth: the Soviets had no contingency plan in place to deal with dental emergencies and Romanenko's ordeal was the subject of a televised interview in his own country and accounts in the Western dental literature. ${ }^{15}$ Although data for US missions are sketchy, 26 instances of infection were reported for American astronauts during the Space Shuttle program STS-1 to STS-89 over the period April 1989 to January $1998 .{ }^{4}$ Routine preflight quarantine has significantly reduced the incidence of infections during missions but the risk remains and is likely to be considerable on future missions into deep space: the spacecraft interior will be contaminated with a wide range of microorganisms; injury and trauma, such as lacerations and open fractures, are likely to occur, and there is strong evidence that extended spaceflight compromises the immune system. ${ }^{16,17}$ In addition, bacteria are adept at adapting to new environments and studies reporting some potentially pathogenic bacteria display increased virulence in microgravity are a further cause for concern. This review will examine the impact of the space flight environment on the capacity of bacteria to cause infections in space farers and will appraise the likely risks for astronauts undertaking extended space flight.

\section{Host factors affecting susceptibility of crew to infection}

Astronauts require a wide range of skills and capabilities in order to perform effectively in the unique closed environment of orbiting spacecraft and to be fit and healthy from both medical and psychological perspectives. The decrease in load bearing for bones of the lower body afforded by reduced gravity results in resorption of bone mineral, muscles weaken and atrophy, fluids are redistributed to the upper body, lengthening of the spine may induce back pain, and the neural circuits that govern balance are disturbed. ${ }^{18}$ These effects are only partly offset by countermeasures that include exercise and pharmaceutical interventions. These physiological changes will have a major impact on the overall health status and are likely to be compounded by enormous psychosocial pressure within small isolated groups, particularly during extended space flight. ${ }^{4}$ The immune system is moderately compromised by space flight, although there is little to suggest flight-induced immune deficits acquired during short- to medium-duration missions result in serious illness. ${ }^{19}$ For example, about half of the astronauts who flew Apollo missions reported minor bacterial or viral infections within a week of their return but the effects were strictly short term..$^{20}$ More recently, reactivation of latent herpes viruses, an indicator of downregulation of cellular immunity, has been noted in crew during flight and within 1 week of return. ${ }^{16,21}$ Mehta et a ${ }^{22}$ recorded subclinical activation of Epstein-Barr virus, varicella-zoster virus, and cytomegalovirus in 14 of 17 astronauts undertaking short-duration flights on board the Space Shuttle, in marked contrast to a terrestrial control group. Thus, the appearance of serious immune-related disorders during extended missions outside LEO cannot be discounted.

Human and animal studies show that space flight or analog environments impact on specific elements of immune function. Modifications include proliferation of human leukocytes in response to mitogenic stimulation, reductions in the synthesis of interferons $\alpha$ and $\beta$, inhibition of natural killer cell activity, depression of delayed-type hypersensitivity reactions, and alteration of leukocyte subpopulations in the marrow and spleen. ${ }^{21}$ As the cellular components of the immune system play a central role in the control of bacterial and viral pathogens, limiting their ability to colonize, invade, and spread within the body, it is significant that space flight induces reversible hypoplasia in the organs of the lymphoid system. After 3 weeks in LEO, the weight of the spleen and thymus of rats was found to be significantly reduced, with accompanying decreases in the number of lymphocytes 
and erythroid cells of the spleen and lymphocytes of the thymus and lymph nodes. ${ }^{23}$ Lymphoid organ hypoplasia has been confirmed in mice on two US Shuttle flights of similar duration to the Soviet mission. ${ }^{24,25}$ In apparent contradiction, there have been a number of consistent reports, summarized by Guéguinou et al, ${ }^{26}$ showing increases in circulating neutrophils of human beings and animals subjected to LEO of varying duration, immediately after landing, although these authors point out that the enormous stress of landing may be responsible for these increases due to mobilization of bone marrow polymorphonuclear leukocytes into the circulation. Space flight suppresses the function of cellular components of both the innate and adaptive immune response. Thus, neutrophils, macrophages, and NK cells respond less readily to various stimuli compared to terrestrial controls ${ }^{17,27,28}$ and T-lymphocytes from space crew display decreased responses to mitogens when harvested after landing. ${ }^{29}$ Interestingly, women demonstrate a stronger immune response to various stimuli than men and this could be taken into account for crew selection. Although inclusion of female crew members has increased in the recent past, there are currently insufficient number of female subjects to determine unequivocally if sex is a factor that impacts significantly on crew wellbeing both during space flight and during the postflight recovery period. ${ }^{30}$

These immune deficits are reminiscent of data from Arctic and Antarctic expedition team members, submariners, and others who may be isolated in time and confined within closed environments ${ }^{31}$ and may be an unavoidable consequence of long periods of isolation or confinement. There are a range of opportunistic pathogens, including bacteria, fungi, and viruses, which depend on reduced immune function to cause serious infectious diseases, and some of them will inevitably accompany the crew into orbit or deep space. The major source of potential infection aboard spacecraft is provided by the astronauts' own bacterial flora. The human body is home to a large and diverse community of microorganisms, collectively termed the microbiome, that play an active role in the development and function of a range of physiological processes of the host, ${ }^{32}$ including the orchestration of the mucosal immune response. ${ }^{33}$ These microbial populations consist largely of bacteria and reside on the skin and in the oral cavity, nasal passages, urogenital tract, and, predominantly, the gastrointestinal (GI) tract. The healthy human adult GI tract contains a complex community of bacteria comprising $\sim 1,000$ species, ${ }^{34}$ and perturbation of this population may result in manifestation of disease. ${ }^{34-36}$ Many of these bacteria cannot be cultured but recent developments in metagenomic technology have enabled detailed analysis of the GI microbial flora by sequence determination of small-subunit ribosomal RNA genes without the need for culture. ${ }^{37}$

Through use of traditional culture techniques, evidence has accumulated that the intestinal bacterial community of crew members undergoes significant change during spaceflight. Early Soviet studies indicated that as early as 2 weeks into confinement on Salyut and Mir orbiting platforms, significant reductions in the number of bacterial species cultured from the GI tract were evident, as was interchange of intestinal bacteria between crew members. ${ }^{38,39}$ In a similar fashion, the number of distinct bacterial species within the GI tract of astronauts on board Apollo and Skylab was markedly reduced and robust Gram-negative aerobic species such as potentially pathogenic Klebsiella and Pseudomonas emerged. ${ }^{20}$ Significant reductions in beneficial intestinal lactobacilli from cosmonauts prior to launch have been recorded, ${ }^{40}$ an indication that preflight stress may drive changes in the composition of the gut microbiota, a view supported by a study under simulated Skylab conditions. ${ }^{41}$ Evidence has emerged of a subtle interplay between the gut microbiota and the immune and endocrine systems in the maintenance of homeostasis; ${ }^{32}$ stress and other potential disrupters of the microbiome-brain-gut axis will impact on the composition of the microbiome and are likely to account for preflight and in-flight changes to the bacterial content of the gut described here, but more work needs to be undertaken in this important area. As of June 2015, no reports using metagenomic analyses of GI microbiota of flight crew have appeared but an on-orbit study of astronaut microbiota using state-of-the-art genetic technology, NASA's Microbiome experiment, ${ }^{42}$ will appear soon.

\section{Impact of the space flight environment on bacterial physiology}

Although bacteria have evolved to survive in sometimes hostile terrestrial niches and will not have previously encountered the environment within the confines of spacecraft traveling beyond Earth's gravitational field, they are able to sense, respond, and adapt to changes in their surroundings. In addition to low or zero gravity, they will be exposed to vibration, acceleration, and radiation in the form of galactic cosmic rays and solar energetic particle events at levels not encountered elsewhere. ${ }^{43}$ There is general agreement that microgravity represents the major influence on bacterial growth kinetics and bacterial cell behavior during short orbital flights, although radiation may increase microbial 
mutation rates during flight: after 40 days aboard Mir, mutation rates for a cloned bacterial gene carried by a yeast were two to three times higher than the ground control. ${ }^{44}$ Investigations conducted during short orbital flights suggest that a range of bacteria display increased metabolic activity in space, manifest as a shorter lag phase, increased biomass, and increased production of secondary metabolites, ${ }^{45-47}$ although some comparable studies reported no differences between flight cultures and terrestrial controls. ${ }^{48,49}$ Some of these observations have been confirmed aboard multiple Space Shuttle flights: the consistency of the data obtained makes it unlikely that disparities of outcome are due to a lack of reproducibility resulting from the technical difficulties inherent in conducting scientific experiments in low gravity, implying that differences in growth media, culture conditions, strain-to-strain variations, and the nature of the bioreactors inside the spacecraft habitat account for differing responses to the space flight environment. ${ }^{43,50}$ Differential impact of bacterial cell behavior in microgravity could be exploited for the production of pharmaceutical compounds, secondary metabolites, and vaccines.

It is clear that earlier predictions ${ }^{51}$ based on theoretical calculations that bacteria are too small to be affected by gravitational forces are incorrect. Klaus et al ${ }^{46}$ and Benoit and $\mathrm{Klaus}^{52}$ have suggested that bacteria are affected only indirectly by microgravity due to the quiescent fluid environment surrounding the cells in liquid suspension culture. The settling of cells through liquid media and the potential for buoyant convection of less dense fluid in the vicinity of suspended bacteria are massively reduced in microgravity, and diffusion becomes the predominant means of nutrient transport toward and of metabolic waste away from the cell..$^{52}$ The view that fluid dynamics and extracellular transport phenomena rather than cellular dynamics contribute to microgravity-induced differences in liquid-culture growth kinetics is supported by observations that bacteria such as Escherichia coli and Bacillus subtilis cultured on solid medium during flight grow at the same rate and to the same extent as terrestrial controls. ${ }^{49,53} \mathrm{~A}$ strong correlation has been noted between the impact of space flight on growth kinetics and bacterial motility, which goes a long way toward explaining differences between flown experiments in this area. ${ }^{52}$ Thus, differences between microgravity-induced growth effects and ground controls seem to be, in the main, evident only when the bacteria under investigation are flagellate: clearly, motile cells have the capacity to seek out microenvironments in liquid cultures that have not been depleted of nutrients and flagellar action may in itself mix the quiescent layer around the cell. Although no definitive experiments have been undertaken to underpin this contention, studies with microgravity analogs such as clinostats and the high aspect ratio vessel (HARV), a rotating wall bioreactor described below, support the idea that mixing of microgravity-grown cultures to eliminate differences in fluid dynamics abrogates these growth kinetic effects.

Alterations in bacterial growth kinetics in space appear to stimulate the production of secondary metabolites. Thus, production of the antibiotic monorden by the parasitic fungus Humicola fuscoatra was greater when grown aboard Space Shuttle mission STS-77 than in ground samples, ${ }^{54}$ even though agar media were employed. Similarly, the time course of elaboration of the antibiotic actinomycin D by Streptomyces plicatus in both defined and complex liquid media was altered in comparison to terrestrial cultures during flight on Shuttle STS-80, with more of the drug produced during the first 12 days in orbit. ${ }^{55,56}$ Interestingly, flight samples maintained their sporulation capacity when plated on agar medium postflight, while the residual ground controls did not sporulate.

Some microorganisms adapt and thrive in the unique environment within spacecraft. A cloudy humidity condensate collected in January 1998 from behind a service panel on the orbiting platform Mir contained a wide range of bacteria, including Gram-negative species only infrequently associated with the contamination of short-duration missions. ${ }^{57}$ One sample yielded evidence of a member of the genus Legionella, bacteria that can cause lethal infections. Microbial consortia that accumulated over the 12 years since the launch of Mir included fungi of medical importance, protozoa, dust mites, and spirochetes. Some bacteria were recovered from surfaces in biofilms, suggesting a microbial strategy for increased onboard survival in comparison to less developed bacterial communities. Pseudomonas aeruginosa PAO-1 formed biofilms more readily than in Earth-based parallel experiments when grown on surfaces or solid medium in the Biorack facility aboard Shuttle missions STS- $81^{58}$ and STS-95. ${ }^{59}$ During later missions STS-132 and STS-135, P. aeruginosa biofilms exhibited a "column and canopy" structure that has not been observed on Earth; ${ }^{60}$ thus, spaceflight affects not only the physiology of planktonic bacterial cultures but also their community-level behavior. A high proportion of Gram-positive isolates from the ISS were able to grow as biofilms under standard laboratory conditions, ${ }^{61}$ suggesting that the capacity to form complex communities on surfaces and interfaces provides competitive advantage aboard spacecraft. 


\section{Microbial contamination of spacecraft}

Spacecraft are manufactured in ultraclean facilities comparable to those used for the manufacture of medicines, and extensive precautions are taken to ensure that levels of microbial contamination are minimized. Until recently, culture-dependent techniques appeared to indicate that the low microbial burden associated with assemblies such as Mars Odyssey comprised predominantly robust, sporulating species of the genus Bacillus but more recent culture-independent studies have revealed a broader range of Gram-positive and Gram-negative bacteria, as well as actinomycetes and fungi. ${ }^{62,63}$ Indeed, a comprehensive investigation of microbial contamination of the Mars rover Curiosity revealed that more than 350 distinct strains of bacteria survived rigorous decontamination in the clean room at NASA's Jet Propulsion Laboratory in Pasadena. ${ }^{64}$ Many such contaminants are resistant to extreme temperatures and ultraviolet-C-mediated damage, ${ }^{62,65}$ and steps are being taken to assemble a genetic inventory of spacecraft contaminants to ensure that attempts to study the potential for indigenous Martian life are not compromised ${ }^{66}$ Although these environmental extremophiles may represent a threat to the fabric of the spacecraft infrastructure through biofouling, they are unlikely to pose a health risk to crew.

A greater microbial risk to crew wellbeing will come from their commensular flora, which will inevitably colonize the spacecraft, and from microbes originating from onboard supplies of air, food, and water. For example, it was reported that potable water generated by the fuel cells aboard Space Shuttle flights was commonly contaminated with very low levels of Burkholderia cepacia and other problematical bacteria. ${ }^{67}$ Similarly, potable water brought from ground sources and stored aboard $\mathrm{Mir}^{67}$ or the ISS $^{68}$ tended to display higher bacterial counts than reclaimed humidity condensate. Future extended duration missions are expected to employ microorganisms for solid waste remediation and as a food source. ${ }^{67}$ On such missions, onboard cultivation of plants as food or as a component of bioregenerative life-support systems together with transportation of associated agricultural materials will further contribute to microbial complexity within such closed environments. The extent and complexity of microbial contamination will increase with time away. Although the potential health impact from the development of diverse microbial populations is unclear, these findings emphasize that microbial monitoring and vessel disinfection are significant factors to be taken into consideration in habitat design, engineering, and operation of all spacecraft.
Threats may come not only from bacteria but also from fungi; dust in HEPA filters from the US laboratory aboard the ISS contained a wide range of potentially pathogenic molds such as Aspergillus flavus and Aspergillus niger and moderate toxin producers such as Penicillium chrysogenum and Penicillium brevicompactum. ${ }^{69}$ Fifteen years of continuous human occupation of the ISS has made the station an excellent test bed for the prediction of microbiological problems that will be encountered during future deep space exploration missions. The approach to microbiological risk on the ISS is one of the prevention rather than reliance on in-flight solutions, and highly efficient air filtration systems, microbiological monitoring, and features to minimize the accumulation of moisture have been incorporated into its design.${ }^{67}$ Nevertheless, the structural and electronic complexities of the various modules that comprise the ISS are so high that routine cleaning of surfaces represents a major "housekeeping" challenge (Figure 1). The initial colonization of surfaces on board the Russian segment of the ISS has recently been investigated: ${ }^{70}$ polymeric materials such as cable-labeling polyimide and the flame-resistant aramid Nomex ${ }^{\circledR}$ were particularly prone to pioneer colonization by dominant Gram-positive members of the genera Staphylococcus, Micrococcus, Bacillus, and Streptococcus, indicating that the skin of crew members represents the primary source of early contamination. Gramnegative bacteria and fungi were also evident.

The international partners on the ISS (NASA, European Space Agency [ESA], Japan Aerospace Exploration Agency [JAXA], and Russian Federal Space Agency [RFSA]) routinely monitor the station to provide essential microbiological information for crew safety. Data for the first 5 years occupation of the Russian segment were revealed in publications from Natalia Novikova of the Russian Academy of Sciences. ${ }^{71,72}$ Some 500 air, water, and surface samples were examined; viable microorganisms in potable water were invariably $<100$ per $\mathrm{mL}$, and the number of airborne bacteria and fungi was 710 and 44 per $^{3}$, respectively. Bacterial contamination of surfaces fluctuated between 25 per $100 \mathrm{~cm}^{3}$ and 43,000 per $100 \mathrm{~cm}^{3}$ according to sampling location. Predominant bacteria were members of the genus Staphylococcus, isolated from $84 \%$ of air and surface samples. Staphylococcus aureus and other opportunistic pathogenic species were frequently recovered. This study established that the environment within the ISS is dominated by bacterial species associated with the skin and mucous membranes of the crew members, in a fashion not dissimilar to that of a medical care unit. In total, $>70$ species of microorganisms were found, about half being bacteria and half fungi, demonstrating the appearance of a 

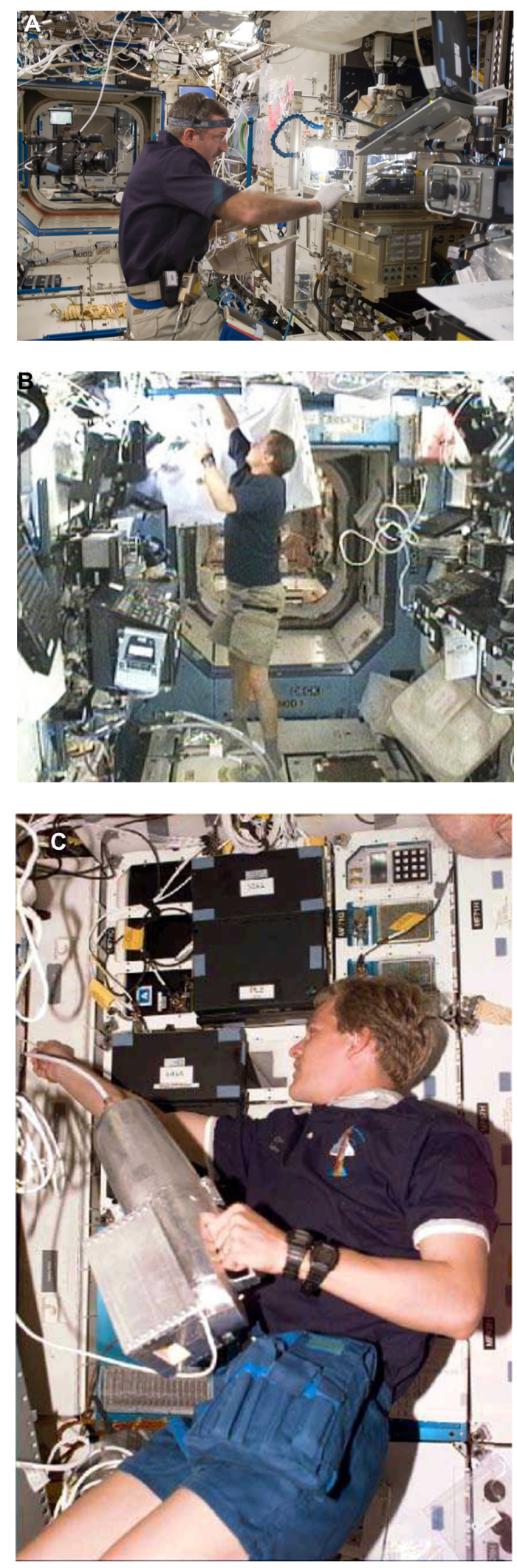

Figure I Internal complexity of the ISS.

Notes: (A) NASA astronaut Dan Burbank, Expedition 30 commander, conducts a session with the Preliminary Advanced Colloids Experiment at the Light Microscopy Module. (B) Expedition 22 flight engineer Tim Creamer works with flex hoses in the ISS's US Destiny laboratory. (C) Using a vacuum cleaner. Courtesy of NASA. Abbreviation: ISS, International Space Station. remarkable biodiversity that had developed over a relatively short period of time. These observations have been confirmed and extended to encompass sampling of NASA's Destiny Laboratory ${ }^{68,73}$ (Figure 1) and JAXA's Kibo facility aboard the ISS. ${ }^{73}$ Again, Staphylococcus, Bacillus, and Micrococcus were the most frequently recovered bacterial genera from air and surface samples between August 1998 and August 2011. Antibiotic resistance appears to be a common trait among these isolates; 22 of 29 Staphylococcus and Enterococcus isolates were resistant to at least one antibiotic deployed aboard the ISS, and most were capable of forming biofilms, ${ }^{61}$ a likely reflection of their capacity to colonize and persist within the orbiting station.

\section{The space flight environment and antibiotic susceptibility}

If infections were to occur on extended missions, their treatment could be compromised by reversible or irreversible increases in antibiotic resistance. Tixador et al, ${ }^{74}$ and Moatti et al, ${ }^{75}$ briefly described some otherwise unpublished observations made during the Apollo-Soyuz Test Project ${ }^{76}$ that bacteria cultured from astronauts during flight were more resistant than isolates obtained from the same individuals either pre- or postflight. These observations prompted the design and execution of experiments to determine the antibiotic susceptibility of $S$. aureus and E. coli isolates from the nasal and GI microbiota of the French astronaut Jean-Loup Chrétien aboard Salyut 7 in July 1982 as part of the Cytos 2 program. Chrétien carried out these experiments during orbital flight, and the data were compared to ground

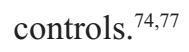

Onboard minimal inhibitory concentrations (MICs) for colistin and kanamycin against the E. coli isolate were reported as $>16 \mu \mathrm{g} / \mathrm{mL}$ compared to control values of $4 \mu \mathrm{g} / \mathrm{mL}$ for both antibiotics. For the $S$. aureus isolate, the ground control values of $0.16 \mu \mathrm{g} / \mathrm{mL}, 4 \mu \mathrm{g} / \mathrm{mL}$, and $0.5 \mu \mathrm{g} / \mathrm{mL}$ against oxacillin, chloramphenicol, and erythromycin, respectively, increased approximately twofold aboard the orbital station. The severe restrictions imposed by space flight and the fact that the laboratory operator was an astronaut rather than a microbiologist determined that the bioassay readouts were based on a $\mathrm{pH}$-induced color change rather than a turbidity endpoint. It is unlikely that the small differences in the staphylococcal MICs are significant given the technical limitations of the bioassay. ${ }^{78}$ Chrétien also embedded the $S$. aureus isolate in resin during the Soyuz 7 flight, and sections were later compared by transmission electron microscopy to ground controls (Figure 2). While 
the terrestrially grown bacteria had an appearance typical of $S$. aureus, with clearly differentiated cell walls and septum formation in the orthogonal plane of cell division, the flown bacteria had an unusual ultrastructure, which has been interpreted as showing a greatly increased thickness of the cell wall peptidoglycan layer, ${ }^{77,79}$ typical of alterations
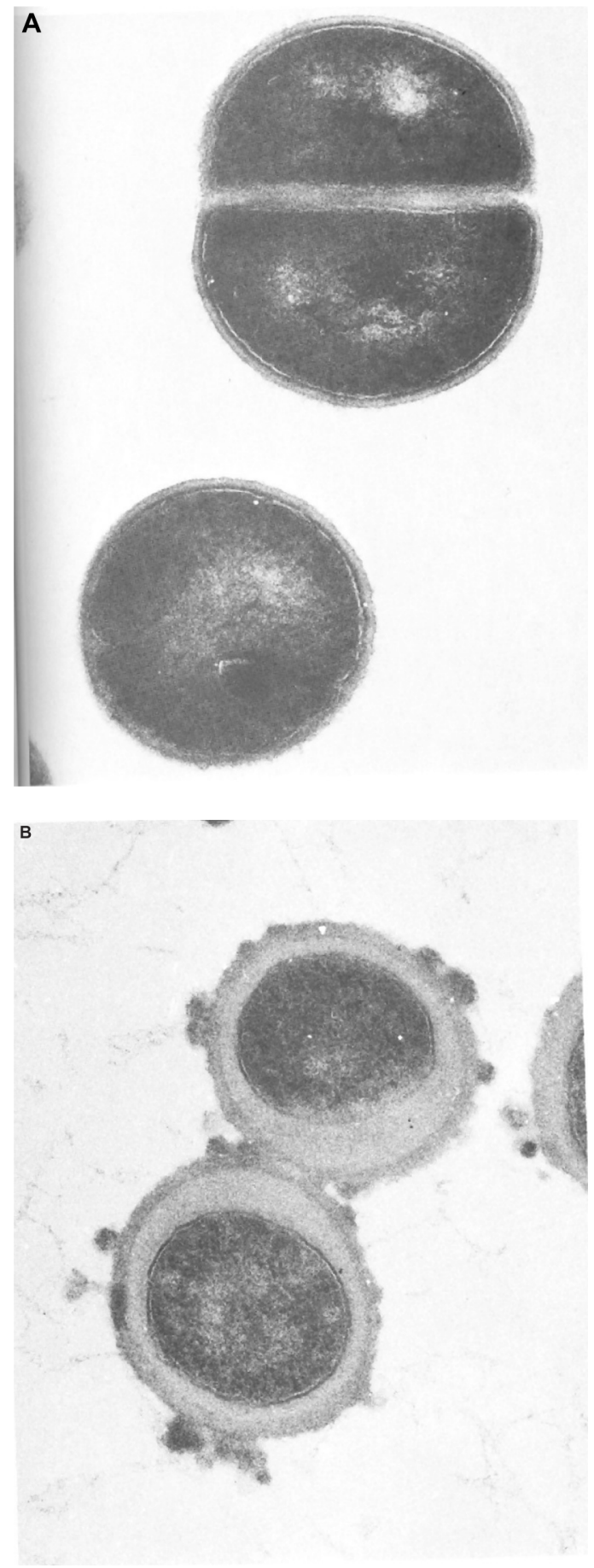

Figure 2 Ultrathin sections of Staphylococcus aureus grown as (A) terrestrial control and (B) in-flight aboard Salyut 7 by Chrétien in 1982 for the Cytos 2 program. Note: Images from Tixador et al ${ }^{77}$ with permission from Elsevier. in vancomycin antibiotic susceptibility. ${ }^{80,81}$ However, the appearance of the in-flight-grown cells has little semblance to conventionally grown staphylococci and the layers external to the cytoplasmic membrane appear less dense than those associated with staphylococci with thickened cell walls caused by phenotype modification. ${ }^{82}$ In addition, the cell surface appears to be blebbing, a phenomenon that occurs during normal growth of Gram-negative bacteria and is enhanced in certain mutants that are impaired in cell division, ${ }^{83}$ suggesting that the bacteria embedded in resin aboard Soyuz 7 are contaminants and not $S$. aureus cells undergoing major, reversible physiological modification due to the impact on morphology of the space flight environment. The changes in antibiotic susceptibility were reversible, as bacteria recovered from the Soyuz 7 flight did not display increased antibiotic susceptibility over ground-based controls when subcultured in a terrestrial laboratory. ${ }^{77}$ In this context, it would be instructive to repeat these experiments aboard the ISS using more recently developed in-flight methodologies in order to resolve this important issue.

The difficulties encountered in such in-flight experiments are illustrated by additional work undertaken in November 1985 aboard Space Shuttle Challenger flight STS-61-A during the ESA Biorack program Antibio ${ }^{79}$ and Discovery flight STS-42 as part of the International Microgravity Laboratory mission in January $1992,{ }^{84}$ both to determine, in fairly restricted fashion, the impact of space flight on antibiotic susceptibility. Both flights included onboard centrifugal controls to allow for additional effects such as vibration and acceleration relative to ground controls. The MIC of E. coli Seattle 1946 (ATCC 25922) against colistin was determined aboard STS-61-A on a static rack under microgravity and on an in-flight centrifuge at $1 \times g$. Although published details are sketchy, ${ }^{79}$ a colorimetric procedure similar to that of the earlier Franco-Soviet flight was used and the data compared to static rack $1 \times g$ and $1.4 \times g$ centrifugal Earth controls. Both in-flight determinations (microgravity and $1 \times g$ ) gave MICs of $2 \mu \mathrm{g} / \mathrm{mL}$; these values were double those obtained with both Earth controls, ${ }^{79}$ suggesting that factors other than those relating to the gravitational field were responsible for these small, possibly insignificant, differences. Large, 100fold differences in colony forming units counts between in-flight (higher) and ground controls (lower) at corresponding inhibitory concentrations were claimed ${ }^{79}$ but no details of any standardization of respective inocula were provided, and it is well established, as detailed in the section Impact of the space flight environment on bacterial physiology of this review, that bacteria have the capacity to grow faster under 
microgravity, particularly under static growth conditions. Although it is tempting to conclude that these data are indicative of a microgravity-induced increase in antibiotic resistance, ${ }^{79,85}$ it should be treated with caution. Similarly, differences in the growth rate of the $E$. coli Seattle strain in the presence and absence of subinhibitory concentrations of dihydrostreptomycin aboard STS-42 produced inconclusive results when in-flight and ground controls were compared. MICs appeared identical $(8 \mu \mathrm{g} / \mathrm{mL})$ between ground and flight determinations, although there were differences in growth curve profiles at $6 \mu \mathrm{g} / \mathrm{mL}$ that suggested subtle changes in the interaction between the antibiotic and the ribosomal target. In agreement with the study conducted within the Antibio program, no differences were observed between cultures developed in-flight in the $1 \times g$ centrifuge and those placed in the static rack under reduced gravity. Kacena and Todd, ${ }^{86}$ in demonstrating that E. coli grown on solid agar medium aboard STS-69 and STS-73 were as susceptible to gentamicin as ground controls, highlighted the caution to be taken in the interpretation of in-flight antibiotic sensitivity testing, particularly when suspension culture is used. The anomalies generated by this confusing body of work can only be completely resolved by further in-flight experimentation undertaken in systematic fashion. Unfortunately, opportunities for experimentation aboard orbiting stations are currently very limited.

\section{Bacterial growth under modeled microgravity: virulence and antibiotic susceptibility}

The space flight environment is inherently complex, with multiple variables that include zero and microgravity, acceleration, vibration, radiation, electromagnetism, and additional environmental stresses associated with the closed environment of the space vehicle, and cannot therefore be simulated in its entirety. ${ }^{87}$ These factors may impact individually on bacterial physiology and result in changes to gene expression and behavior, but their combined effect can only be examined simultaneously during actual space flight. Examination of space flight parameters are limited by the constraints of in-flight experimentation, such as requirements for the development of specialized equipment and restrictions imposed on power, weight, and volume. The intense competition for the crew's time dictates that experiments are simple to perform with little or no crew involvement. These severe limitations can be overcome to a considerable extent through the use of ground-based devices that simulate individual aspects of space.
Clinostats and other rotating wall bioreactors such as the HARV have stimulated a large body of research into the impact of modeled microgravity on the physiology of a wide range of unicellular ${ }^{85}$ and multicellular ${ }^{88}$ cells, including microorganisms. The HARV, developed at the NASA Johnson Space Center, ${ }^{89}$ consists of a hollow cassette completely filled with growth medium that slowly rotates on an axis parallel to the ground; under these conditions, the bacteria are continually suspended in the medium, falling through a sustained low-shear $\left(<1 \mathrm{dyn} / \mathrm{cm}^{2}\right)$ environment that simulates true microgravity. Thus, this low-shear modeled microgravity (LSMMG) device uses constant reorientation in suspension culture to effectively nullify cumulative sedimentation of particles but cannot fully reproduce the concurrent lack of structural deformation, displacement of intercellular components, and reduced mass transfer in the extracellular fluid that occur in the true weightless environment. ${ }^{90}$ When the HARV is employed in the LSMMG orientation with the axis of rotation at $25 \mathrm{rpm}$ and perpendicular to the direction of the gravity force vector, the bioreactor simulates a gravitational field of $\sim 0.01 \times g,{ }^{91}$ rotating the vessel in the normal gravity orientation at $90^{\circ}$ to the perpendicular, the axis of rotation is parallel to the gravity vector, providing a $1 \times g$ control that can be run in parallel with LSMMG cultures. The engineering principles behind these devices, that create a low-shear mixed fluid environment optimized for suspension culture, have been described in detail in two excellent reviews. ${ }^{89,90}$

In a comprehensive series of publications, Nickerson et al have explored the impact of growth in ground-based microgravity analogs on the virulence of Salmonella enterica serovar Typhimurium, a human and animal pathogen that frequently causes GI infections. Time to death of mice administered LSMMG-grown cells by the oral route was shorter in comparison to the same dose of $1 \times g$ control bacteria; LSMMG-grown bacteria more readily colonized the liver and spleen, possessed a decreased $\mathrm{LD}_{50}$, and were more acid resistant. It is not clear how the bacteria grown under LSMMG conditions maintained their microgravity phenotype throughout the 20-day period of the mouse virulence assay; ${ }^{92}$ they would be expected to revert to normal phenotype after reencountering $1 \times g$ conditions, but they may have retained the induced phenotype for sufficient time to enable them to pass through the acidic environment of the stomach. LSMMG differentially regulated the expression of 163 genes representing functionally diverse activities, ${ }^{93}$ and it was proposed that modeled microgravity elicits a novel environmental signal, possibly mediated by the fur product, which regulates virulence, stress resistance, and protein 
expression in $S$. enterica, enabling the cell to "fine tune" the expression of virulence mechanisms in novel fashion. This ground-based data enabled the evaluation of transcriptomic and proteomic responses of $S$. enterica aboard Space Shuttle flight STS-115;94 167 transcripts and 73 proteins were found to display altered expression in comparison to ground control cultures, and the conserved RNA-binding protein Hfq was identified as a likely global regulator of the flight-induced response.

The LSMMG response appears to be conserved by other Gram-negative bacteria. ${ }^{95}$ However, as discussed above, Gram-positive bacteria such as $S$. aureus are likely to pose a much greater risk of opportunistic infection to the crew than S. enterica, which is unlikely to be encountered during space flight. Taylor and Rosado ${ }^{96-98}$ examined the effect of simulated microgravity in the HARV on parameters of antibiotic susceptibility and virulence in methicillin-susceptible clinical isolates of $S$. aureus. Only very small differences in growth kinetics over the 24-hour culture period were seen with the three isolates, and there were no significant differences in susceptibility to erythromycin, flucloxacillin, or vancomycin when cells were grown under LSMMG compared to normal gravity; the antibiotics were selected on the basis of their differing mechanisms of action. In marked contrast to the images obtained from S. aureus cultured aboard Salyut 7 (Figure 2), there were no discernible differences in staphylococcal cell morphology as revealed by scanning and transmission electron microscopy. The three $S$. aureus isolates produced the carotenoid pigment staphyloxanthin, a triterpenoid esterified with a $\mathrm{C} 15$ fatty acid and linked to staphylococcal virulence; 99 all three isolates produced less staphyloxanthin when grown under simulated microgravity compared to normal gravity cells. Large decreases in total protein secretion and in the elaboration of extracellular $\alpha, \beta, \gamma$, and $\delta$ hemolysins were also evident. There was, however, only a modest reprograming of gene expression in all strains with up to 25 genes differentially expressed under LSMMG. The only common feature among the three isolates examined was a substantial downregulation of $v r a X$, a gene encoding a small (55 amino acids) compact polypeptide that is massively upregulated in the stress response to cell wall-active antibiotics ${ }^{100}$ and other surface-interactive molecules. ${ }^{101}$ VraX harbors a putative phosphorylation site, ${ }^{102}$ and could therefore be involved in regulatory processes within the cell, although a $\Delta v r a X$ mutant did not appear to differ from the wild type with respect to protein secretion and had no influence of the expression of other staphylococcal genes under the experimental conditions used. ${ }^{98}$ The $\operatorname{VraX}$ data suggest that $S$. aureus grown under LSMMG may not respond to environmental stresses as well as under normal gravity conditions, and the accumulative data on the impact of microgravity indicate that staphylococci display a biofilm/colonization phenotype with reduced virulence characteristics. Strong evidence in favor of a LSMMG-induced biofilm/colonization phenotype has also been obtained by Castro et al: ${ }^{103}$ they found that a methicillin-resistant $S$. aureus (MRSA) displayed slower growth and repressed virulence characteristics when grown under low-shear conditions, including decreased carotenoid production, increased susceptibility to oxidative stress, and reduced survival in whole blood. Transcriptional profiling and expression analysis suggested alterations in metabolic pathways and downregulation of the RNA chaperone Hfq, which parallels low-fluid-shear responses of Gram-negative organisms. ${ }^{94,104}$

Further evidence that Gram-positive, Gram-negative bacteria, and yeasts are less, not more, virulent than $1 \times g$ controls when grown under microgravity conditions has emerged from careful studies of the capacity of Listeria monocytogenes, MRSA, Enterococcus faecalis, and Candida albicans to kill Caenorhabditis elegans nematodes at the larval and adult stages on the ISS and under clinorotation. ${ }^{105}$ Spaceflight reduced the virulence of the four microorganisms for both larval and adult C. elegans, and clinorotation reproduced the effects of spaceflight in some, but not all, virulence assays: $C$. albicans and $E$. faecalis were less virulent for larval worms but not adult worms, whereas the virulence of MRSA and L. monocytogenes were unaffected by clinorotation with both adult and larval worms. The authors concluded that these four common clinical microorganisms are all less virulent in space. Thus, both true and simulated space flight environments alter the interactions between host and virulent bacteria, and recent evidence suggests that the same may be true for animal-bacterial symbiosis, ${ }^{106}$ with implications for human space flight. These authors investigated the impact of simulated microgravity on the timeline of bacteria-induced development in the host light organ, the site of the symbiosis between the squid Euprymna scolopes, and the luminescent bacterium Vibrio fischeri. The host and symbiosis-competent bacteria were incubated together in the HARV and examined during the early stages of bacteriainduced morphogenesis. The host innate immune response was suppressed under simulated microgravity, and there was an acceleration of bacteria-induced apoptosis and regression in host tissues, indicating that LSMMG may alter cellular interactions between animal hosts and their natural healthy microbiome. 
The virulence of Yersinia pestis, the plague bacillus, has also been examined under LSMMG with regard to its virulence characteristics ${ }^{107}$ in order to gain insights into its pathogenesis. LSMMG-grown cells possessed decreased HeLa cell toxicity and proliferated less than normal gravity controls in the murine macrophage cell line RAW264.7 as a consequence of altered type three secretion system (T3SS) function. Thus, a growing body of evidence suggests that spaceflight and simulated microgravity conditions reduce, not increase, the capacity of pathogenic bacteria (and also yeast) to cause infections; this may reduce the risk of infection for those undertaking extended space flight, although mutation to drug-resistant genotypes during flight may counter this presumption. Clearly, much more work needs to be undertaken in this area and agreement should be reached on the precise techniques that will enable meaningful comparisons between future studies. True and simulated microgravity engender a unique bacterial phenotype that may enable the unraveling of mechanisms of microbial pathogenesis and drug-bacteria interactions, extending the value of such studies into the realms of nosocomial and community-acquired human infections on Earth.

\section{The space flight environment and drug stability: implications for anti-infective chemotherapy}

The risk of both superficial and systemic infections will increase with mission duration, ${ }^{4,43,96}$ and the high likelihood of eye injuries, trauma, and fractures will require antibiotic prophylaxis. The onboard pharmacy available to ISS crew has been expanded and refined during more than 50 years of space faring and its composition reflects the likelihood that specific adaptations to microgravity and the health risks associated with spaceflight will require frequent therapeutic interventions. Although ISS crew members typically spend 6 months aboard before returning to Earth, comprehensive plans are in place for immediate emergency evacuation should the need arise. ${ }^{9}$ Expeditions beyond Earth orbit will present enormous health and medical care challenges; lunar missions will last weeks or months, and Martian expeditions will be of 2-3 years duration with little or no opportunity for evacuation of sick crew members. ${ }^{4}$

The use of pharmaceutical preparations has increased with mission length. During the early stages of US Space Shuttle missions, crews required $>500$ individual doses of 31 different medications; these were administered predominantly by the oral route to $94 \%$ of astronauts. ${ }^{108}$ Although the majority of medicines taken during these flights were well tolerated and presumed effective, $\sim 8 \%$ were reported as nonefficacious. ${ }^{10}$ The large number of pharmaceutical preparations that comprise the current full medical kit aboard the ISS has been described in detail in a recent publication from the staff at the NASA Johnson Space Center. ${ }^{13}$ Antibiotics include amikacin, amoxicillin, co-trimoxazole, topical mupirocin, ciprofloxacin as ophthalmic solution and tablets, cefadroxil, metronidazole, neosporin cream, polymyxin/bacitracin ointment, trimethoprim/polymyxin ophthalmic solution, silver sulfadiazine, tobramycin ophthalmic solution, vancomycin tablets, sulfacetamide/ prednisolone ophthalmic ointment, and azithromycin. The inclusion of antiviral, antifungal, and antiparasitic agents ensures that a wide spectrum of infections can be prevented, treated, and controlled by medications delivered by a variety of routes of administration. The Russian first-aid equipment subsystem provides a similar range of antimicrobial formulations..$^{13}$ All are conventional products from commercial sources manufactured to standards required for treatment of infections on Earth; they have not been optimized for use in LEO or deep space. Further, it is almost certain that changes in human physiology and the composition of the microbiota will affect the absorption, distribution, metabolism, and elimination of drugs taken on board. These important issues have only recently begun to receive the attention they deserve.

Both the physical stability of the formulation and the chemical stability of active ingredients are important in ensuring the safe and efficacious use of pharmaceutical products. ${ }^{14}$ Evidence is emerging that the conditions encountered during even relatively short spaceflight adversely affect pharmaceutical stability, and as a consequence, it is essential to identify drugs that have a reduced shelf life in LEO and deep space and to provide a means for selection and development of medications that will not compromise the success of future missions. In this context, the physical and chemical stabilities and dissolution rates of 35 formulations flown on the ISS have been examined and compared to ground controls using US Pharmacopeia (USP) standard test criteria. ${ }^{109}$ After stowage for 28 months in space, six medications from the space station and two matching ground controls exhibited changes in physical variables; nine medications from the ISS and 17 from the ground met the USP acceptance criteria for content of the active ingredient. A higher percentage of medications from each flight kit showed reductions in active ingredient content compared to the ground control and the number of medications failing this requirement increased as a function of 
time in space. Thus, the rate of degradation of a significant number of these medications was higher in space than on the ground, although most solid dosage forms met standards for dissolution after storage in space. This important publication from Putcha et al proposed that exposure to low doses of ionizing radiation aboard the spacecraft and the repackaging of solid dosage forms in flight-specific dispensers had adversely affected pharmaceutical stability, acting as a wake-up call for the development of space-hardy medications. ${ }^{110}$ The specific contributing factors of the space flight environment that are responsible for pharmaceutical instability are unknown, but candidates include heat, light, vibration, and, particularly, various forms of radiation.

Antibiotic formulations appeared to be prone to degradation in space: clavulanate in amoxicillin/clavulanate formulations, marketed as Augmentin ${ }^{\circledR}$, and sulfamethoxazole in combination tablets did not meet USP tolerance standards after flight and dissolution was very low as a consequence of chemical instability. An earlier study along similar lines from $\mathrm{Du}$ et $\mathrm{al}^{111}$ further established the relative instability of antibiotic formulations aboard Space Shuttles and the ISS; significant reductions in the percentage label claim for the active ingredient were found for amoxicillin capsules and ciprofloxacin ointment, and these formulations failed to meet regulatory standards post flight. The implications are clear: commercially available formulations of established antibiotics may not be sufficiently robust to withstand extended forays into deep space and use may cause treatment failure. Production of bioactive agents from natural product sources could be undertaken during extended flight ${ }^{112}$ and may represent an alternative source of valuable anti-infective compounds. In a similar fashion, the threat of treatment failure during extended flight could be ameliorated by therapeutic modalities that are currently attracting interest for the treatment of terrestrial infections, such as photodynamic therapy, bacteriophage therapy, and attenuation of bacterial virulence by selective removal of key bacterial virulence determinants such as the protective surface capsule that allows many pathogens to avoid the immune defenses of the host. ${ }^{112,113}$

\section{Conclusion}

The risk of serious infection for spaceflight crew members will grow as we journey beyond LEO and into deep space. Our ability to treat infections on these journeys may be compromised by changes to human physiology and to bacterial phenotypes induced by the unique properties of the space flight environment. The susceptibility of opportunistic pathogens to conventional antibiotics may change under the influence of microgravity and virulence-related characteristics of bacteria - fellow-travelers on board the spacecraft - may alter. No clear consensus has emerged from the limited amount of data currently available regarding long-term risk to crew, and more work needs to be undertaken to gain a clearer picture of the threat posed by microorganisms in space.

\section{Disclosure}

The author reports no conflicts of interest in this work.

\section{References}

1. Review of US Human Spaceflight Plans Committee. Seeking a Human Spaceflight Program Worthy of a Great Nation. Washington, DC: Review of US Human Spaceflight Plans Committee; 2009.

2. O'Leary B. Mining the apollo and amor asteroids. Science. 1977; 197(4301):363-366.

3. Khan A. Firm aims to mine asteroids to refuel, build metal parts in space. Los Angeles Times. January 22, 2013.

4. Ball JR, Evans CH. Safe Passage: Astronaut Care for Exploration Missions. Washington DC: National Academy Press; 2001.

5. Stewart LH, Trunkey D, Rebagliati GS. Emergency medicine in space. J Emerg Med. 2007;32(1):45-54.

6. Horneck G, Facius R, Reichert M, et al. HUMEX, a study on the survivability and adaptation of humans to long-duration exploratory missions. I: lunar missions. Adv Space Res. 2003;31:2389-2401.

7. Horneck G, Facius R, Reichert M, et al. HUMEX, a study on the survivability and adaption of humans to long-duration exploratory missions, part II: missions to Mars. Adv Space Res. 2006;38:752-759.

8. Horneck G, Comet B. General human health issues for Moon and Mars missions: results from the HUMEX study. Adv Space Res. 2006;37: 100-108.

9. NASA. Final Report of the International Space Station Independent Safety Task Force. Washington, DC: NASA; 2007.

10. Putcha L, Berens KL, Marshburn TH, Ortega HJ, Billica RD. Pharmaceutical use by US astronauts on space shuttle missions. Aviat Space Environ Med. 1999;70(7):705-708.

11. Houtchens B. System for the Management of Trauma and Emergency Surgery in Space: Final Report. Houston: NASA, Johnson Space Center; 1983.

12. Grigoriev AI, Orlov OI. Telemedicine and spaceflight. Aviat Space Environ Med. 2002;73(7):688-693.

13. Taddeo TA, Armstrong CW. Spaceflight medical systems. In: Barratt MR, Pool SL, editors. Principles of Clinical Medicine for Space Flight. New York: Springer; 2008:69-100.

14. Taylor PW, Putcha L. Stability of medications in space: therapeutic implications for extended duration space missions. In: Petrova VM, editor. Advances in Engineering Research. Vol 1. Hauppauge: Nova Science Publishers; 2012:221-239.

15. Wheatcroft W. Effects of simulated Skylab missions on the oral health of astronauts. J Gr Houston Dental Soc. 1989;61:7.

16. Sonnenfeld G, Shearer WT. Immune function during space flight. Nutrition. 2002;18(10):899-903.

17. Rykova MP, Antropova EN, Larina IM, Morukov BV. Humoral and cellular immunity in cosmonauts after the ISS missions. Acta Astronaut. 2008;63(7-10):697-705.

18. Williams DR. The biomedical challenges of space flight. Ann Rev Med. $2003 ; 54: 245-256$.

19. Taylor GR. Immune changes during short-duration missions. J Leukoc Biol. 1993;54(3):202-208.

20. Taylor GR. Recovery of medically important microorganisms from Apollo astronauts. Aerospace Med. 1974;45(8):824-882. 
21. Stowe RP, Mehta SK, Ferrando AA, Feeback DL, Pierson DL. Immune responses and latent herpesvirus reactivation in spaceflight. Aviat Space Environ Med. 2001;72(10):884-891.

22. Mehta SK, Laudenslager ML, Stowe RP, Crucian BE, Sams CF, Pierson DL. Multiple latent viruses reactivate in astronauts during space shuttle missions. Brain Behav Immun. 2014;41:210-217.

23. Durnova GN, Kaplansky AS, Portugalov VV. Effect of a 22-day space flight on the lymphoid organs of rats. Aviat Space Environ Med. 1976;47(6):588-591.

24. Gridley DS, Nelson GA, Peters LL, et al. Genetic models in applied physiology: selected contribution: effects of spaceflight on immunity in the C57BL/6 mouse. II. Activation, cytokines, erythrocytes, and platelets. J Appl Physiol. 2003;94(5):2095-2103.

25. Baqai FP, Gridley DS, Slater JM, et al. Effects of spaceflight on innate immune function and antioxidant gene expression. J Appl Physiol. 2009;106(6):1935-1942.

26. Guéguinou N, Huin-Schohn C, Bascove M, et al. Could spaceflightassociated immune system weakening preclude the expansion of human presence beyond Earth's orbit? J Leukoc Biol. 2009;86(5): 1027-1038.

27. Kaur I, Simons ER, Castro VA, Ott CM, Pierson DL. Changes in monocyte functions of astronauts. Brain Behav Immun. 2005;19(6):547-554.

28. Kaur I, Simons ER, Kapadia AS, Ott CM, Pierson DL. Effect of spaceflight on ability of monocytes to respond to endotoxins of gram-negative bacteria. Clin Vaccine Immunol. 2008;15(10):1523-1528.

29. Cogoli A, Tschopp A, Fuchs-Bislin P. Cell sensitivity to gravity. Science. 1984;225(4658):228-230.

30. Kennedy AR, Crucian B, Huff JL, et al. Effects of sex and gender on adaptation to space: immune system. JWomens Health (Larchmt). 2014; 23(11):956-958.

31. Williams DR. Isolation and integrated testing: an introduction to the Lunar-Mars life support test project. In: Lane HW, Sauer RL, Feeback DL, editors. Isolation - NASA Experiments in Closed-Environment Living, Science and Technology Series. Vol 104. San Diego: Univelt Inc.; 2002:1-6.

32. Moloney RD, Desbonnet L, Clarke G, Dinan TG, Cryan JF. The microbiome: stress, health and disease. Mamm Genome. 2014;25(1-2): 49-74.

33. O'Hara AM, Shanahan F. Gut microbiota: mining for therapeutic potential. Clin Gastroenterol Hepatol. 2007;5(3):274-284.

34. Xu J, Gordon JI. Honor thy symbionts. Proc Natl Acad Sci U S A. 2003;100(18):10452-10459.

35. Wen L, Ley RE, Volchkov PY, et al. Innate immunity and intestinal microbiota in the development of Type 1 diabetes. Nature. 2008; 455(7216):1109-1113.

36. van Vliet MJ, Harmsen HJM, de Bont ES, Tissing WJ. The role of intestinal microbiota in the development and severity of chemotherapyinduced mucositis. PLoS Pathog. 2010;6(5):e1000879.

37. Eckburg PB, Bik EM, Bernstein CN, et al. Diversity of the human intestinal microbial flora. Science. 2005;308(5728):1635-1638.

38. Nefedov YG, Shilov VM, Koustantinova IV, Zaloguev SN. Microbiological and immunological aspects of extended manned space flights. Life Sci Space Res. 1971;9:11-16.

39. Ilyin VK. Microbiological status of cosmonauts during orbital spaceflights on Salyut and Mir orbital stations. Acta Astronaut. 2005; 56(9-12):839-850.

40. Lencner AA, Lencner CP, Mikelsaar ME, et al. Die quantitative Zusammensetzung der Lactoflora des Verdauungstrakt vor und nach kosmischen Flügen unterschiedlicher Dauer [The quantitative composition of the intestinal lactoflora before and after space flights of different lengths]. Nahrung. 1984;28(6-7): 607-613. German.

41. Holdeman LV, Good IJ, Moore WEC. Human fecal flora: variation in bacterial composition within individuals and a possible effect of emotional stress. Appl Environ Microbiol. 1976;31(3):359-375.

42. NASA. Study of the impact of long-term space travel on the astronauts' microbiome (Microbiome). Houston: National Aeronautics and Space Administration. Available from: http://www.nasa.gov/mission_pages/ station/research/experiments/1010.html. Accessed January 28, 2015.
43. Horneck G, Klaus DM, Mancinelli RL. Space microbiology. Microbiol Mol Biol Rev. 2010;74(1):121-156.

44. Fukuda T, Fukuda K, Takahashi A, et al. Analysis of deletion mutations of the rpsL gene in the yeast Saccharomyces cerevisiae detected after long-term flight on the Russian space station Mir. Mutat Res. 2000;470:125-132.

45. Mishra SK, Pierson DL. Space flight, effects on microorganisms. In: Lederberg J, editor. Encyclopedia of Microbiology. Vol 4. San Diego: Academic Press; 1992:53-60.

46. Klaus DM, Simske S, Todd P, Stodieck L. Investigation of space flight effects on Escherichia coli and a proposed model of underlying physical mechanisms. Microbiology. 1997;143(2):449-455.

47. Klaus DM. Space microbiology: microgravity and microorganisms. In: Britton G, editor. Encyclopedia of Environmental Microbiology. Vol 6. New York: John Wiley; 2002:2996-3004.

48. Gasset G, Tixador R, Eche B, et al. Growth and division of Escherichia coli under microgravity conditions. Res Microbiol. 1994; 145(2):111-120.

49. Kacena MA, Todd P. Growth characteristics of E. coli and B. subtilis cultured on an agar substrate in microgravity. Microgravity Sci Technol. 1997;10(1):58-62.

50. Kim W, Tengra FK, Shong J, et al. Effect of spaceflight on Pseudomonas aeruginosa final cell density is modulated by nutrient and oxygen availability. BMC Microbiol. 2013;13:241.

51. Pollard EC. Theoretical studies on living systems in the absence of mechanical stress. J Theor Biol. 1965;8(1):113-123.

52. Benoit MR, Klaus DM. Microgravity, bacteria, and the influence of motility. Adv Space Res. 2007;39:1225-1232.

53. Kacena MA, Leonard PE, Todd P, Luttges MW. Low gravity and inertial effects on the growth of E. coli and B. subtilis. Aviat Space Environ Med. 1997;68(12):1104-1108.

54. Lam KS, Mamber SW, Pack EJ, Forenza S, Fernandes PB, Klaus DM. The effects of space flight on the production of monorden by Humicola fuscoatra WC5157 in solid-state fermentation. Appl Microbiol Biotechnol. 1998;49(5):579-583.

55. Lam KS, Gustavson DR, Pirnik DL, et al. The effect of space flight on the production of actinomycin D by Streptomyces plicatus. $J$ Ind Microbiol Biotechnol. 2002;29(6):299-302.

56. Benoit MR, Li W, Stodieck LS, et al. Microbial antibiotic production aboard the International Space Station. Appl Microbiol Biotechnol. 2006;70(4):403-411.

57. Ott CM, Bruce RJ, Pierson DL. Microbial characterization of free floating condensate aboard the Mir Space Station. Microb Ecol. 2004;47(2):133-136.

58. Leys NMEJ, Hendrickx L, de Boever P, Baatout S, Mergeay M. Space flight effects on bacterial physiology. J Biol Reg Homeostat Agents. 2004;18:193-199.

59. McLean RJ, Cassanto JM, Barnes MB, Koo JH. Bacterial biofilm formation under microgravity conditions. FEMS Microbiol Lett. 2001; 195(2):115-119.

60. Kim W, Tengra FK, Young Z, et al. Spaceflight promotes biofilm formation by Pseudomonas aeruginosa. PLoS One. 2013; 8(4):e62437.

61. Schiwon K, Arends K, Rogowski KM, et al. Comparison of antibiotic resistance, biofilm formation and conjugative transfer of Staphylococcus and Enterococcus isolates from International Space Station and Antarctic Research Station Concordia. Microb Ecol. 2013; 65(3):638-651.

62. La Duc MT, Nicholson W, Kern R, Venkateswaran K. Microbial characterization of the Mars Odyssey spacecraft and its encapsulation facility. Environ Microbiol. 2003;5(10):977-985.

63. La Duc MT, Kern R, Venkateswaran K. Microbial monitoring of spacecraft and associated environments. Microb Ecol. 2004;47(2): $150-158$.

64. Madhusoodanan J. Microbial stowaways to Mars identified. Nature. 2014. Available from http://www.nature.com/news/microbialstowaways-to-mars-identified-1.15249. 
65. McCoy KB, Derecho I, Wong T, et al. Insights into the extremotolerance of Acinetobacter radioresistens 50v1, a gram-negative bacterium isolated from the Mars Odyssey spacecraft. Astrobiology. 2012;12(9): 854-862.

66. La Duc MT, Venkateswaran K, Conley CA. A genetic inventory of spacecraft and associated surfaces. Astrobiology. 2014;14(1):15-23.

67. Pierson DL. Microbial contamination of spacecraft. Gravit Space Biol Bull. 2001;14(2):1-6.

68. Castro VA, Thrasher AN, Healy M, Ott CM, Pierson DL. Microbial characterization during the early habitation of the International Space Station. Microb Ecol. 2004;47(2):119-126.

69. Vesper SJ, Wong W, Kuo CM, Pierson DL. Mold species in dust from the International Space Station identified and quantified by moldspecific quantitative PCR. Res Microbiol. 2008;159(6):432-435.

70. Reidt U, Helwig A, Plobner L, et al. Study of initial colonization by environmental microorganisms in the Russian segment of the International Space Station (ISS). Gravit Space Res. 2014;2(2):46-57.

71. Novikova ND. Review of the knowledge of microbial contamination of the Russian manned spacecraft. Microb Ecol. 2004;47(2):127-132.

72. Novikova N, De Boever P, Poddubko S, et al. Survey of environmental biocontamination on board the International Space Station. Res Microbiol. 2006;157(1):5-12.

73. Yamaguchi N, Roberts M, Castro S, et al. Microbial monitoring of crewed habitats in space-current status and future perspectives. Microbes Environ. 2014;29(3):250-260.

74. Tixador R, Richoilley G, Gasset G, et al. Study of minimal inhibitory concentration of antibiotics on bacteria cultured in vitro in space (Cytos 2 experiment). Aviat Space Environ Med. 1985;56(8):748-751.

75. Moatti N, Lapchine L, Gasset G, Richoilley G, Templier J, Tixador R. Preliminary results of the "Antibio" experiment. Naturwissenschaften. 1986;73(7):413-414.

76. Taylor GR, Zaloguev SN. Methods for microbiological and immunological studies of space flight crews. NASA Technical Memorandum NASA-TMX-58185; 1978. Available from: http://ntrs.nasa.gov/archive/ nasa/casi.ntrs.nasa.gov/19780021782.pdf. Accessed April 8, 2015.

77. Tixador R, Richoilley G, Gasset G, et al. Preliminary results of Cytos 2 experiment. Acta Astronaut. 1985;12(2):131-134.

78. Andrews JM. Determination of minimum inhibitory concentrations $J$ Antimicrob Chemother. 2001;48(Suppl 1):5-16. [Erratum in: J Antimicrob Chemother. 2002;49(6):1049].

79. Lapchine L, Moatti N, Gasset G, Richoilley G, Templier J, Tixador R. Antibiotic activity in space. Drugs Exptl Clin Res. 1985;12(12):933-938.

80. Sieradzki K, Pinho MG, Tomasz A. Inactivated pbp4 in highly glycopeptide-resistant laboratory mutants of Staphylococcus aureus. J Biol Chem. 1999;274(27):18942-18946.

81. Sieradzki K, Tomasz A. Alterations of cell wall structure and metabolism accompany reduced susceptibility to vancomycin in an isogenic series of clinical isolates of Staphylococcus aureus. J Bacteriol. 2003; 185(24):7103-7110.

82. Hamilton-Miller JMT, Shah S. Disorganisation of cell division of methicillin-resistant Staphylococcus aureus by a component of tea (Camellia sinensis): a study by electron microscopy. FEMS Microbiol Lett. 1999;176(2):463-469.

83. Typas A, Banzhaf M, Gross CA, Vollmer W. From the regulation of peptidoglycan synthesis to bacterial growth and morphology. Nat Rev Microbiol. 2012;10(2):123-136.

84. Tixador R, Gasset G, Eche B, et al. Behavior of bacteria and antibiotics under space conditions. Aviat Space Environ Med. 1994;65(6): 551-556.

85. Nickerson CA, Ott CM, Wilson JW, Ramamurthy R, Pierson DL. Microbial responses to microgravity and other low-shear environments. Microbiol Mol Biol Rev. 2004;68(2):345-361.

86. Kacena MA, Todd P. Gentamicin: effect on E. coli in space. Micrograv Sci Technol. 1999;12(3-4):135-137.

87. Guo J, Han N, Zhang Y, et al. Use of genome sequencing to assess nucleotide structure variation of Staphylococcus aureus strains cultured in spaceflight on Shenzhou-X, under simulated microgravity and on the ground. Microbiol Res. 2015;170:61-68.
88. Barrila J, Radtke AL, Crabbé A, et al. Organotypic 3D cell culture models: using the rotating wall vessel to study host-pathogen interactions. Nat Rev Microbiol. 2010;8(11):791-801.

89. Hammond TG, Hammond JM. Optimized suspension culture: the rotating-wall vessel. Am J Physiol Renal Physiol. 2001;281(1): F12-F25.

90. Klaus DM. Clinostats and bioreactors. Gravit Space Biol Bull. 2001;14(2):55-64.

91. Schwarz RP, Goodwin TJ, Wolf DA. Cell culture for three-dimensional modeling in rotating-wall vessels: an application of simulated microgravity. J Tissue Cult Methods. 1992;14(2):51-57.

92. Nickerson CA, Ott CM, Mister SJ, Morrow BJ, Burns-Keliher L, Pierson DL. Microgravity as a novel environmental signal affecting Salmonella enterica serovar Typhimurium virulence. Infect Immun . 2000;68(6):3147-3152.

93. Wilson JW, Ramamurthy R, Porwollik S, et al. Microarray analysis identifies Salmonella genes belonging to the low-shear modelled microgravity regulon. Proc Natl Acad Sci U S A. 2002;99(21): 13807-13812.

94. Wilson JW, Ott CM, Höner zu Bentrup K, et al. Space flight alters bacterial gene expression and virulence and reveals a role for global regulator Hfq. Proc Natl Acad Sci U S A. 2007;104(41): 16299-16304.

95. Soni A, O’Sullivan L, Quick LN, Ott CM, Nickerson CA, Wilson JW. Conservation of the low-shear modeled microgravity response in Enterobacteriaceae and analysis of the trp genes in this response. Open Microbiol J. 2014;8:51-58.

96. Taylor PW, Rosado H. Manned missions to Mars - the likely impact of microbial infection. In: Costas LA, editor. Planet Mars Research Focus. Hauppauge: Nova Science Publishers; 2008:165-185.

97. Rosado H, Doyle M, Hinds J, Taylor PW. Low-shear modelled microgravity alters expression of virulence determinants by Staphylococcus aureus. Acta Astronaut. 2010;66(3-4):408-413.

98. Rosado H, O’Neill AJ, Blake K, et al. Rotating wall vessel alters protein secretion and global gene expression by Staphylococcus aureus. Int J Astrobiol. 2012;11(2):71-81.

99. Liu GY, Essex A, Buchanan JT, et al. Staphylococcus aureus golden pigment impairs neutrophil killing and promotes virulence through its antioxidant activity. J Exp Med. 2005;202(2):209-215.

100. Utaida S, Dunman PM, Macapagal D, et al. Genome-wide transcriptional profiling of the response of Staphylococcus aureus to cell-wallactive antibiotics reveals a cell-wall-stress stimulon. Microbiology. 2002;149(10):2719-2732.

101. Bernal P, Lemaire S, Pinho MG, Mobashery S, Hinds J, Taylor PW. Insertion of epicatechin gallate into the cytoplasmic membrane of methicillin-resistant Staphylococcus aureus disrupts penicillin-binding protein (PBP) 2a-mediated $\beta$-lactam resistance by delocalizing PBP2. J Biol Chem. 2010;285:24055-24065.

102. Scherl A, François P, Charbonnier Y, et al. Exploring glycopeptideresistance in Staphylococcus aureus: a combined proteomics and transcriptomics approach for the identification of resistance-related markers. BMC Genom. 2006;7:296.

103. Castro SL, Nelman-Gonzalez M, Nickerson CA, Ott CM. Induction of attachment-independent biofilm formation and repression of $\mathrm{Hfc}$ expression by low-fluid-shear culture of Staphylococcus aureus. Appl Environ Microbiol. 2011;77(18):6368-6378.

104. Crabbé A, Schurr MJ, Monsieurs P, et al. Transcriptional and proteomic responses of Pseudomonas aeruginosa PAO1 to spaceflight conditions involve Hfq regulation and reveal a role for oxygen. $\mathrm{Appl}$ Environ Microbiol. 2011;77(4):1221-1230.

105. Hammond TG, Stodieck L, Birdsall HH, et al. Effects of microgravity on the virulence of Listeria monocytogenes, Enterococcus faecalis, Candida albicans, and methicillin-resistant Staphylococcus aureus. Astrobiology. 2013;13(11):1081-1090.

106. Foster JS, Khodadad CL, Ahrendt SR, Parrish ML. Impact of simulated microgravity on the normal developmental time line of an animalbacteria symbiosis. Sci Rep. 2013;3:1340. 
107. Rosenzweig JA, Chopra AK. The effect of low shear force on the virulence potential of Yersinia pestis: new aspects that space-like growth conditions and the final frontier can teach us about a formidable pathogen. Front Cell Infect Microbiol. 2012;2:107.

108. Tietze KJ, Putcha L. Factors affecting drug availability in space. J Clin Pharmacol. 1994;34:671-676.

109. Du B, Daniels VR, Vaksman Z, Boyd JL, Crady C, Putcha L. Evaluation of physical and chemical changes in pharmaceuticals flown on space missions. AAPS J. 2011;13(2):299-308.

110. Putcha L, Taylor PW, Boyd JL. Biopharmaceutical challenges of therapeutics in space: formulation and packaging considerations. Ther Deliv. 2011;2(11):1373-1376.
111. Du J, Gatlin K, Vaksman Z, Berens K, Putcha L. Stability of pharmaceuticals during space flight. AAPS Pharm Sci. 2002;4:T3153.

112. Taylor PW, Sommer AP. Towards rational treatment of bacterial infections during extended space flight. Int J Antimicrob Agents. 2005; 26:183-187.

113. Taylor PW, Bernal P, Zelmer A. Modification of the bacterial phenotype as an approach to counter the emergence of multidrug-resistant pathogens. In: Bonilla AR, Muniz KP, editors. Antibiotic Resistance: Causes and Risk Factors, Mechanisms and Alternatives. Hauppauge: Nova Science Publishers; 2009:43-78.

\section{Publish your work in this journal}

Infection and Drug Resistance is an international, peer-reviewed openaccess journal that focuses on the optimal treatment of infection (bacterial, fungal and viral) and the development and institution of preventive strategies to minimize the development and spread of resistance. The journal is specifically concerned with the epidemiology of antibiotic

\section{Dovepress}

resistance and the mechanisms of resistance development and diffusion in both hospitals and the community. The manuscript management system is completely online and includes a very quick and fair peerreview system, which is all easy to use. Visit http://www.dovepress.com/ testimonials.php to read real quotes from published authors.

Submit your manuscript here: http://www.dovepress.com/infection-and-drug-resistance-journal 